\title{
Start-up and Performance Characteristics of a Trickle Bed Reactor Degrading Toluene
}

\author{
Ondřej Misiaczek ${ }^{1}$, Jan Paca ${ }^{1}$, Martin Halecký ${ }^{1}$, Andrew Mark Gerrard ${ }^{2}$, Miroslav \\ Sobotka $^{3}$ and Carlos Riccardo Soccol ${ }^{4}$ \\ ${ }^{1}$ Institute of Chemical Technology; Department of Fermentation Chemistry and Bioengineering; Technicka 5, 166 \\ 28; jan.paca@vscht.cz; Prague - Czech Republic. ${ }^{2}$ University of Teesside; Middlesbrough, TS1 3BA, England. \\ ${ }^{3}$ Institute of Microbilology; Academy of Sciences; Vídeňská 1083, 142 20; Prague - Czech Republic. ${ }^{4}$ Universidade \\ Federal do Paraná; Centro Politécnico - Jardim das Américas; C.P.: 19011; 81531-970; Curitiba - PR - Brasil
}

\begin{abstract}
The objective of this work was to evaluate toluene degradation in a trickle bed reactor when the loading was carried out by changing the air flow rate. The biofiltration system was inoculated with a mixed microbial population, adapted to degradation of hydrophobic compounds. Polypropylene high flow rings were used as a packing material. The system was operated for a period of 50 days at empty bed residence times ranging from 106s to $13 \mathrm{~s}$ and with a constant inlet concentration of toluene of $100 \mathrm{mg} . \mathrm{m}^{-3}$. The reactor showed high removal efficiency at higher contact times and increasing elimination capacity with higher air-flow rates. The highest EC value reached was $9.8 g_{C} . m$ ${ }^{3} \cdot h^{-1}$ at EBRT $=13 \mathrm{~s}$. During the experiment, the consumption of $\mathrm{NaOH}$ solution was also measured. No significant variation of this value was found and an average value of $3.84 \mathrm{mmol}$ of $\mathrm{NaOH}$ per gram of consumed carbon was recorded.
\end{abstract}

Key words: Biotrickling filter, constructed mixed population, toluene, air flow rate loading

\section{INTRODUCTION}

Toluene is a noncorrosive, volatile liquid with an aromatic odour which is widespread in the environment because of its use in a wide variety of commercial and household products (Fishbein, 1985). It is used as an additive in gasoline mixtures to increase octane ratings, in benzene production, and as a solvent in paints, coatings, inks, adhesives, and cleaners. Additionally, it is used in the production of nylon, plastics, and polyurethanes (U.S. EPA, 2005). But the largest amounts of toluene get into the environment in the form of benzene, toluene, ethylbenzene and xylenes mixtures (BTEX). The main source of
BTEX contamination is the leakage of gasoline from underground storage tanks, releases from large bulk facilities, surface spills of petroleum products and pipeline leaks. It has been shown that toluene has several unfavorable effects on human health. An extensive database on human exposure to toluene indicates that dysfunction of the central nervous system is of primary concern (WHO, 2000).

Biofiltration has proved to be a suitable method for the removal of volatile organic compounds (VOCs) from the environment. The degradation of VOCs by microorganisms is affected by various environmental factors such as moisture content, temperature, $\mathrm{pH}$ and accessibility of the target

\footnotetext{
${ }^{*}$ Author for correspondence
} 
substance. Biofiltration is also affected by the kind of contaminant and VOC input rate. Therefore, maintenance of the biofilter conditions suitable for the microbial activity is essential for successful operation (Spain and van Veld, 1983).

Despite a large number of publications on biofiltration of toluene (Cox and Deshusses, 1999, Cox et al., 1998, Schönduve et al., 1996, Smith et al., 1996), only a few authors described treatment of toluene contaminated air in trickle bed reactors at short empty bed residence times (EBRT). Pedersen and Arvin (1995) studied the performance of the trickle bed system under different inlet concentrations and gas flow rates and used first and zero order kinetics to evaluate simple analytical models. For loads in the range from 6 to $150 \mathrm{~g} \cdot \mathrm{m}^{-3} \cdot \mathrm{h}^{-1}$ the maximum elimination capacity was $35 \pm 10 \mathrm{~g} \cdot \mathrm{m}^{-3} \cdot \mathrm{h}^{-1}$, corresponding to a zero order removal rate of $0.11 \pm 0.03 \mathrm{~g} \cdot \mathrm{m}^{-2} \cdot \mathrm{h}^{-1}$ per unit of nominal surface area. In order to prevent the reactor from clogging, nutrient limiting conditions were used in bacterial and fungal biotrickling filters operated at EBRT of 36s. A better overall performance of the fungi inoculated reactor has been reported (Weber and Hartmans, 1996).

\section{MATERIALS AND METHODS}

A schematic diagram of the biofiltration system used in experiments is shown in Fig. 1. A glass column of ID $=150 \mathrm{~mm}$ and height of $1.7 \mathrm{~m}$ was filled with hydrophilized high-flow rings (polypropylene, $25 \mathrm{~mm} \times 25 \mathrm{~mm} \times 1 \mathrm{~mm}$, void fraction of $92 \%$, specific surface area of $214 \mathrm{~m}^{2} . \mathrm{m}$ ${ }^{3}$, Rauschert Verfahrenstechnik GmbH, Germany) to a height of $1 \mathrm{~m}$. For the inoculation of the system, a mixed microbial consortium was used. The following strains were selected for the inoculation because of their ability to degrade toluene as a sole carbon and energy source for growth: Bacillus cereus (G+ rods), Comamonas testosteroni (G- rods), Pseudomonas putida montelii (G- rods), Pseudomonas putida atypical (G- rods), Sphingobacterium multivorum (Grods).

The pure bacterial strains were stored in a deep freezer at $-70^{\circ} \mathrm{C}$. The inoculation suspension was prepared using submerged cultivations with toluene vapor as the sole carbon and energy source. The cultivations were performed in triplicate in $500 \mathrm{ml}$ Erlenmeyer flasks with working volume of $100 \mathrm{ml}$ at $26^{\circ} \mathrm{C}$ in rotary shaker. The medium composition for cultivation consisted of (g. $\left.\mathrm{L}^{-1}\right): \mathrm{K}_{2} \mathrm{HPO}_{4} 4.3 ; \mathrm{KH}_{2} \mathrm{PO}_{4}$ 3.4; $\mathrm{KNO}_{3} 2 ; \mathrm{MgCl}_{2} .6 \mathrm{H}_{2} \mathrm{O} ; 0.34 ; \mathrm{FeSO}_{4} 6.10^{-4}$; $\mathrm{Na}_{2} \mathrm{MoO}_{4}$ 1.10-5. A basic synthetic medium $(0.4$ g.L ${ }^{-1}\left(\mathrm{NH}_{4}\right)_{2} \mathrm{SO}_{4}, 0.3$ g.L. $\mathrm{KNO}_{3}, 0.1$ g.L $\mathrm{L}^{-1} \mathrm{NaCl}$, 0.125 g.L $\mathrm{L}^{-1} \quad \mathrm{~K}_{2} \mathrm{HPO}_{4}, 0.085$ g.L $\mathrm{L}^{-1} \mathrm{KH}_{2} \mathrm{PO}_{4}, 0.34$ g. $\mathrm{L}^{-1} \mathrm{MgCl}_{2} \cdot 6 \mathrm{H}_{2} \mathrm{O}$ and $1 \mathrm{ml} . \mathrm{L}^{-1}$ trace elements) represented the liquid circulation content which was periodically added to the reactor to keep the volume at $5 \mathrm{~L}$. The liquid flow rate was equal to $4.10^{-2} \mathrm{~m}^{3} \cdot \mathrm{h}^{-1}$ during the whole experiment. The bioreactor was equiped with a $\mathrm{pH}$ control to maintain the value of $\mathrm{pH}=7$ and was operated at temperature of $22^{\circ} \mathrm{C}$ in a counter current mode. The consumption of $\mathrm{NaOH}$ solution used for $\mathrm{pH}$ control and pressure drop were both measured during the experiment.

The synthetic waste gas influent included toluene (technical grade). The toluene concentration in the gas phase was measured using an Agilent $6890 \mathrm{~N}$ gas chromatograph equipped with an ultra alloy- 5 (5\% phenylmethylsilicone) capillary column $30 \mathrm{~m}$ in length, $0.53 \mathrm{~mm}$ inner, and with a $1.5 \mu \mathrm{m}$ film thickness (Quadrex Corp., UA5 - 30V - $1.5 \mathrm{~F}$, New Haven, CT). The carrier gas used was ultra high purity argon at a flow rate of $5 \mathrm{ml} \cdot \mathrm{min}^{-1}$. Detection was accomplished with a flame ionization detector (FID) with ultra high purity hydrogen and breathing quality air at flow rates of $28 \mathrm{ml} \cdot \mathrm{min}^{-1}$ and $315 \mathrm{ml} \cdot \mathrm{min}^{-1}$, respectively. GC operating conditions were: column temperature, $80^{\circ} \mathrm{C}$; FID temperature, $250^{\circ} \mathrm{C}$.

In this study, the following terms for performance calculations are defined as:

Elimination capacity, EC

$$
E C=\left(C_{\text {in }}-C_{\text {out }}\right) \cdot \frac{Q}{V_{b}} \quad\left(g_{c} \cdot m^{-3} \cdot h^{-1}\right)
$$

Organic load, OL

$$
O L=C_{i n} \cdot \frac{Q}{V_{b}} \quad\left(g_{c} \cdot m^{-3} \cdot h^{-1}\right)
$$

Removal efficiency, RE

$$
R E=\frac{E C}{O L} \cdot 100
$$


$\mathrm{C}_{\text {in }}, \mathrm{C}_{\text {out }}$ - inlet and outlet pollutant $\left(\mathrm{g}_{\mathrm{C}} \cdot \mathrm{m}^{-3}\right), \mathrm{Q}$ - air flow rate $\left(\mathrm{m}^{3} \cdot \mathrm{h}^{-1}\right), \mathrm{V}_{\mathrm{b}}$ - filter bed volume $\left(\mathrm{m}^{3}\right)$.

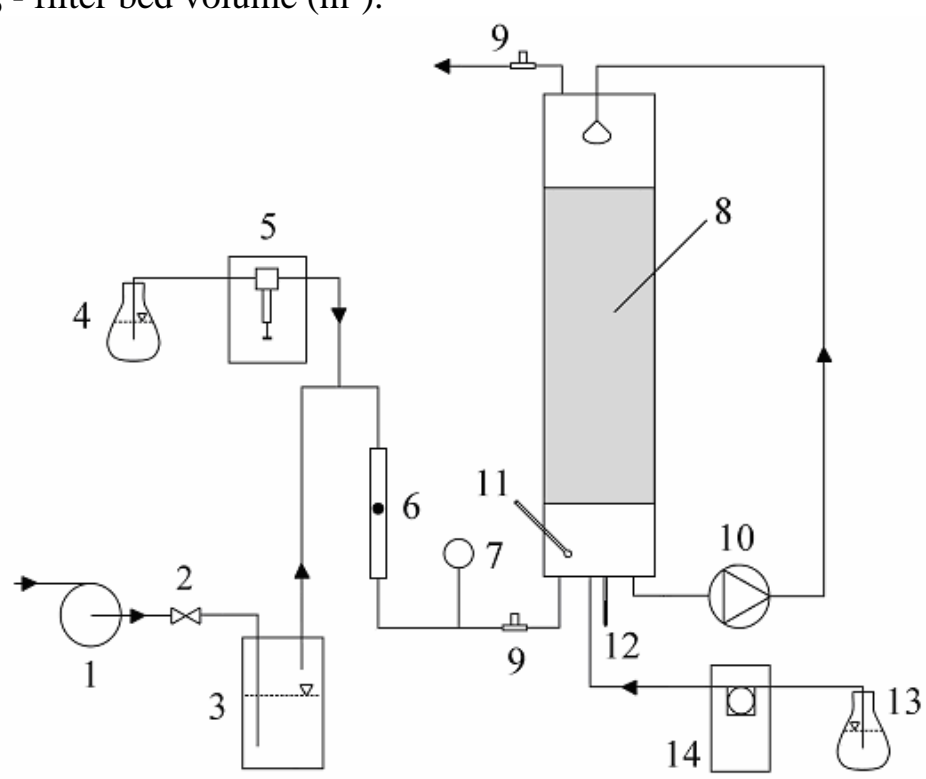

Figure 1 - Bioreactor set-up 1 - blower, 2 - needle valves for flow rate control, 3 - humidification vessel, 4 - vessel with toluene, 5 - syringe pump, 6 - rotameter, 7 - manometer, 8 packing, 9 - sampling ports, 10 - membrane pump, 11 - pH electrode (Pt), 12 thermometer, 13 - $\mathrm{NaOH}$ solution, 14 - peristaltic pump

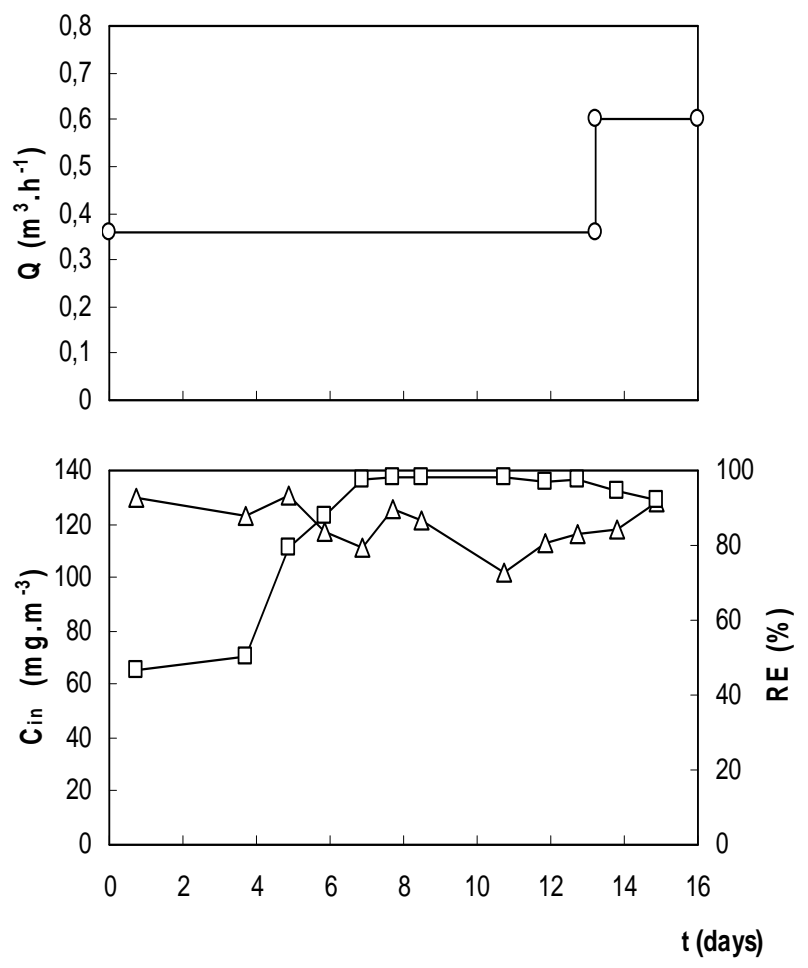

Figure 2 - Acclimation period $\odot$ - air flow rate, $\Delta$ - inlet concentration of toluene,,$\square$ removal efficiency 


\section{RESULTS AND DISCUSSION}

Fig. 2 shows the start-up period of the experiment. The starting empty bed retention time (EBRT) was $177 \mathrm{~s}$ (air-flow rate of $0.36 \mathrm{~m}^{3} \cdot \mathrm{h}^{-1}$ ) and inlet concentration of toluene, which was the only carbon and energy source during the whole time of operation, was kept between 100 and $130 \mathrm{mg} \cdot \mathrm{m}^{-3}$. Under these conditions, the biotrickling filter reached a RE of $97 \%$ in seven days of operation. During the next week, the removal efficiency stayed stable and did not drop below 97\%. A slight decrease of RE was reported at day 14, after the EBRT had been shortened to $106 \mathrm{~s}$ (air-flow rate of $\left.0.6 \mathrm{~m}^{3} \cdot \mathrm{h}^{-1}\right)$.

In the following 32 days of operation, the system was loaded by the air flow rate with a constant toluene inlet concentration of $100 \mathrm{mg} \cdot \mathrm{m}^{-3}$ (Fig. 3). The air flow rate had been gradually increased in four equal steps (each time by $0.6 \mathrm{~m}^{3} \cdot \mathrm{h}^{-1}$ ) from 0.6 $\mathrm{m}^{3} \cdot \mathrm{h}^{-1}$ to $3 \mathrm{~m}^{3} \cdot \mathrm{h}^{-1}$ (i.e. EBRT of $106 \mathrm{~s}$ to $21 \mathrm{~s}$, respectively) and subsequently in six equal steps (each time by $0.3 \mathrm{~m}^{3} \cdot \mathrm{h}^{-1}$ ) from $3 \mathrm{~m}^{3} \cdot \mathrm{h}^{-1}$ to $4.8 \mathrm{~m}^{3} \cdot \mathrm{h}^{-}$ ${ }^{1}$ (i.e. EBRT of $13 \mathrm{~s}$ ).

The performance characteristics are shown in Figure 4. As expected, the highest values of RE > $80 \%$ were obtained at the values of EBRTs in a range of 35 - 106s i.e., up to OL about $10 \mathrm{~g}_{\mathrm{C}} \cdot \mathrm{m}^{-3} \cdot \mathrm{h}^{-}$ 1. Exceeding this loading rate, the removal efficiency started to decrease. The lowest RE, recorded at EBRT of $13 \mathrm{~s}$, was $37.5 \%$. These rather low values of $\mathrm{RE}$ are probably due to the combined impact of several parameters. The first is the relatively short EBRT values. The other reason could be a relatively low quantity of the biocatalyst (in the form of biofilm) after three weeks of operation. The main reason for this arises from the overall surface area of the packing material. The high-flow rings used in this study have a much smaller surface area in comparison to other materials such as peat (Morales et al., 1998), compost (Delhomenie et al., 2003), vermiculite (Ortiz et al., 2003), perlite (Arriaga and Revah, 2005), activated carbon (Li et al., 2002).

The elimination capacity rose with the increasing loading rate up to an $\mathrm{OL}$ of $20 \mathrm{~g}_{\mathrm{C}} \cdot \mathrm{m}^{-3} \cdot \mathrm{h}^{-1}$. No further increase of EC values has been observed for EBRTs shorter than 16s. The highest EC value was $9.8 \mathrm{~g}_{\mathrm{c}} \cdot \mathrm{m}^{-3} \cdot \mathrm{h}^{-1}$. Therefore, an EBRT of $35 \mathrm{~s}$ was the optimal value for this system, with respect to sufficient air cleaning at a good elimination capacity of $7.5 \mathrm{~g}_{\mathrm{C}} \cdot \mathrm{m}^{-3} \cdot \mathrm{h}^{-1}$.

The use of this packing material, together with a low salt concentration in the circulating medium, resulted in keeping the pressure drop low (without any substantial increase as time progressed) and therefore no biomass removal was needed.

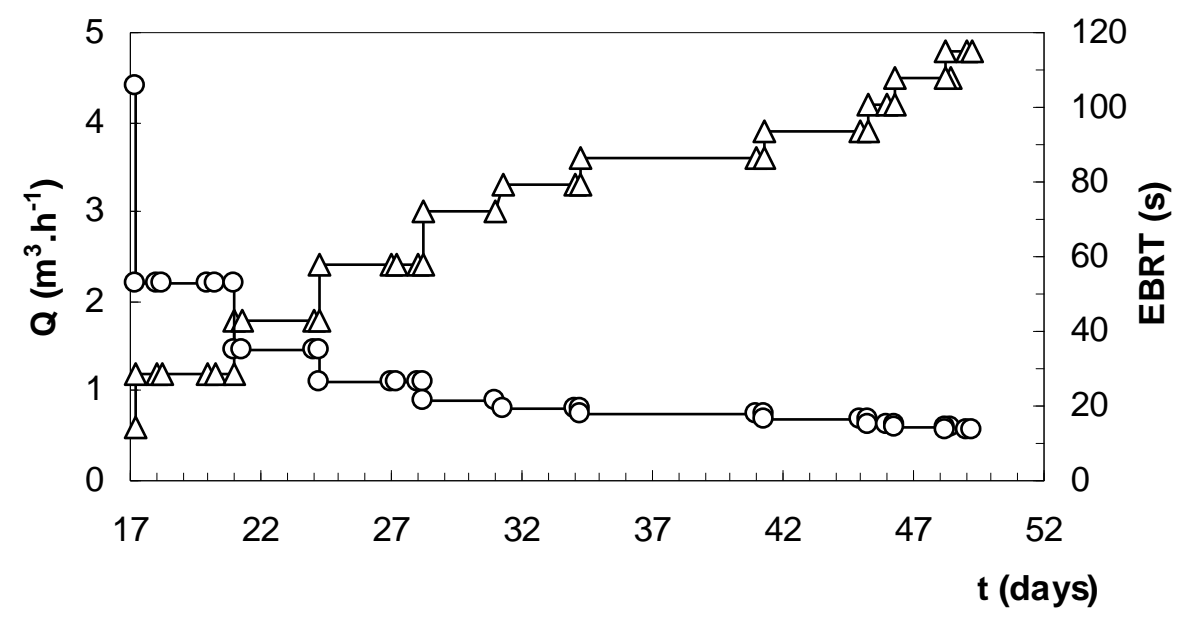

Figure 3 - Loading profiles $\circ$ - EBRT, $\Delta$ - air flow rate 

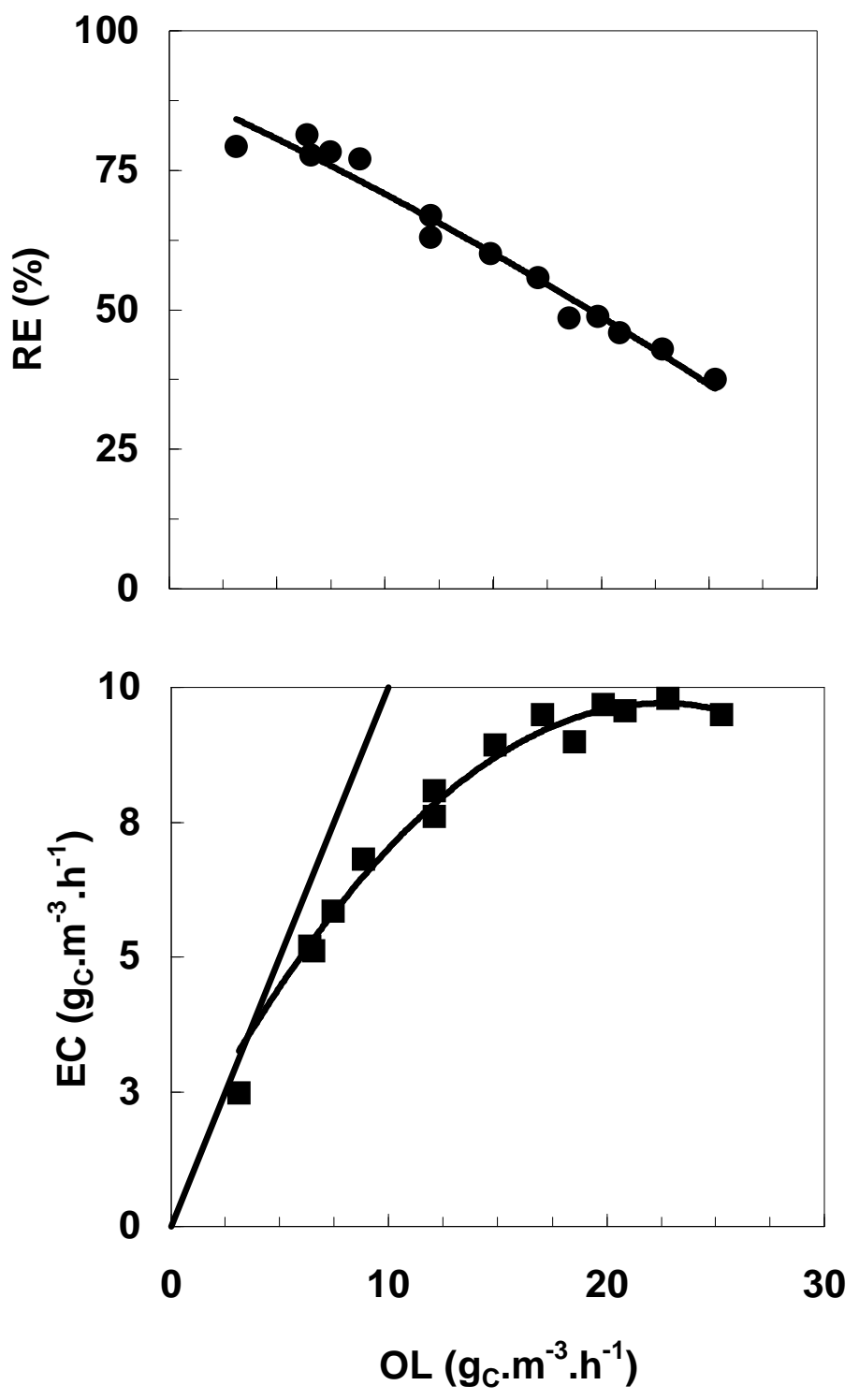

Figure 4 - Performance characteristics

Klapkova (2005) who studied the degradation of toluene in trickle bed reactor packed with $15 \mathrm{~mm}$ Pall rings during air-flow rate loading experiments achieved a higher EC (of $20 \mathrm{~g}_{\mathrm{c}} \cdot \mathrm{m}^{-3} \cdot \mathrm{h}^{-1}$ ) at the same organic load. In addition, there was a significant difference in the pressure drop measured during her experiments. For example, the pressure drop (at EBRT of 13s) was $700 \mathrm{~Pa}$ in her study which is far higher than the $100 \mathrm{~Pa}$ recorded in our experiments. The differences in the EC values as well as those of pressure drop demonstrate well the effect of the overall surface area and void volume in the two packings. The much higher content of biomass in the Klapkova system explains the higher elimination capacities reached.

Sakuma et al. (2006) tested toluene removal in biofilters at EBRTs of 13.5 and 27s. Four packing materials were investigated: Cattle bone Porcelite (CBP), a composite ceramic; Porcelite, a porous ceramic; horticultural perlite and open-pore polyurethane foam (PUF). The results are difficult to compare with ours, due to the missing values of the particle specific surface area for each of their packing materials. They found that $\mathrm{CBP}$ showed the best properties. At EBRT of $13.5 \mathrm{~s}$ the reactor packed with CBP was able to operate at RE $>98 \%$ at $\mathrm{OL}$ around $25 \mathrm{~g} \cdot \mathrm{m}^{-3} \cdot \mathrm{h}^{-1}$ and even at an OL of 
$70 \mathrm{~g}_{\mathrm{C}} \cdot \mathrm{m}^{-3} \cdot \mathrm{h}^{-1}$ the system demonstrated a high RE values. The Perlite and PUF packed biofilters showed significantly worse performance at the same toluene loadings (RE of 60 and 40\%, respectively).

Weber and Hartmans (1996) who studied the degradation of toluene using $50 \mathrm{~mm}$ Pall rings as a packing material obtained an elimination capacity of $8 \mathrm{~g}_{\mathrm{C}} \cdot \mathrm{m}^{-3} \cdot \mathrm{h}^{-1}$ at organic load of $11 \mathrm{~g}_{\mathrm{C}} \cdot \mathrm{m}^{-3} \cdot \mathrm{h}^{-1}$ and EBRT of 36s. In our experiments, an EC of 6.8 $\mathrm{g}_{\mathrm{C}} \cdot \mathrm{m}^{-3} \cdot \mathrm{h}^{-1}$ was reached under similar conditions. Their higher EC value can be explained by their (almost twice) larger total surface area. The biofilter system, loaded by air flow rate, was able to operate steadily with a removal efficiency close to $100 \%$ at EBRT of 101, 50, 14 and $7 \mathrm{~s}$ and comparable organic loads (Zilli et al., 2001). On the other hand, it should be noted that these results were obtained using a richer salt medium where the bed consisted of a mixture of sterilized peat (with a specific surface area of $1.6 \mathrm{~m}^{2} \cdot \mathrm{g}^{-1}$ ) and glass beads of $5 \mathrm{~mm}$ in a 4:1 volume ratio, with a much higher surface area.

From the amount of $\mathrm{NaOH}$ solution used and the elimination capacity values, we calculated the consumption of $\mathrm{NaOH}$ per gram of carbon consumed. During the experiment no significant fluctuation of this quantity was found. An average value of $3.84 \mathrm{mmol}$ of $\mathrm{NaOH}$ per gram of consumed carbon was determined.

\section{CONCLUSIONS}

A relatively short start-up period of the system was observed. After a week of operation, the reactor achieved a stable removal efficiency above 95\%. The increasing air-flow rate (reducing the contact time between the pollutant and the biocatalyst) was shown to have a significant effect on the degradation efficiency. The relatively low removal efficiencies achieved and the small pressure drop indicate a low concentration of biomass in the system, resulting from both the short time for biofilm formation and the low specific surface area of the packing material. The higher the air flow rate, the more important this factor seems to be. It was found that different contact times did not effect the consumption of $\mathrm{NaOH}$ per gram of toluene carbon consumed.

\section{Symbols}

Cin, Cout - inlet and outlet concentration $\left(\mathrm{g}_{\mathrm{C}} \cdot \mathrm{m}^{-3}\right)$

EBRT - empty bed residence time (s)

EC - elimination capacity $\left(\mathrm{g}_{\mathrm{C}} \cdot \mathrm{m}^{-3} \cdot \mathrm{h}^{-1}\right)$

ID - inner diameter $(\mathrm{mm})$

$\mathrm{OL}$ - organic load $\left(\mathrm{g}_{\mathrm{C}} \cdot \mathrm{m}^{-3} \cdot \mathrm{h}^{-1}\right)$

$\mathrm{Q}$ - air flow rate $\left(\mathrm{m}^{3} \cdot \mathrm{h}^{-1}\right)$

$\mathrm{V}_{\mathrm{b}}$ - filter bed volume $\left(\mathrm{m}^{3}\right)$

$\mathrm{RE}$ - removal efficiency (\%)

\section{ACKNOWLEDGEMENTS}

The work was financially supported by the Czech Science Foundation, Join Project 104/05/0194 and by the Ministry of Education of the Czech Rep., Project MSM 6046137305.

\section{REFERENCES}

Arriaga, S. and Revah, S. (2005), Improving hexane removal by enhancing fungal development in a microbial consortium biofilter. Biotechnol. Bioeng., 90, 107-115.

Cox, H. H. J. and Deshusses, M. A. (1999), Biomass control in waste air biotrickling filters by protozoan predation. Biotechnol. Bioeng., 62, 216-224.

Cox, H. H. J.; Nguyen, T. T. and Deshusses, M. A. (1998), Elimination of toluene vapors in biotrickling filters: Performance and carbon balances, Paper 98WAA.04P. In: Proceedings of the Annual Meeting and Exhibition of the Air and Waste Management Association, June 15-17, 1998, San Diego, CA.

Delhomenie, M. C.; Bibeau, L.; Gendron, J.; Brzezinski, R. and Heitz, M. (2003), Degradation of toluene, xylene, and trimethyl. benzene vapors by biofiltration: A comparison. J. Air Waste Manage Assoc., 53, 217-226.

Fishbein, L. (1985), An overview of environmental and toxicological aspects of aromatic hydrocarbons II. Toluene. Science of the Total Environmental, 42, 267-288.

Klapkova, E. (2005), An application of biotrickling filter in the process of degradation of hydrofobic and hydrofilic volatile compounds, $\mathrm{PhD}$ Thesis, ICT Prague, Department of Fermentation Chemistry and Bioengineering, Prague, Czech Republic.

Li, G-W.; Hu, H-Y.; Hao, J-M. and Fujie, K. (2002), Use of biological activated carbon to treat mixed gas of toluene and benzene in biofilter. Environ. Technol., 23, 467-477.

Morales, M.; Revah, S. and Auria, R. (1998), Start-up and the effect of gaseous ammonia addition on a biofilter for the elimination of toluene vapours. Biotechnol. Bioeng., 60, 483-491. 
Ortiz, I.; Revah, S. and Auria, R. (2003), Effects of packing material on the biofiltration of benzene, toluene and xylene vapours. Environ. Technol., 24, 265-275.

Pedersen, A. R. and Arvin, E. (1995), Removal of toluene in waste gases using a biological trickling filter. Biodegradation, 6, 109-118.

Sakuma, T.; Hattori, T. and Deshusses M. A. (2006), Comparison of different packing materials for the biofiltration of air toxics. J. Air Waste Manage. Assoc., 56, 1567-1575.

Schönduve, P.; Sára, M. and Friedl, A. (1996), Influence of physiologically relevant parameters on biomass formation in a trickle-bed bioreactor used for waste gas cleaning. Appl. Microbiol. Biotechnol., 45, 286-292.

Smith, F. L.; Sorial, G. A.; Suidan, M. T.; Breen, A. W.; Biswas, P. and Brenner, R. C. (1996), Development of two biomass control strategies for extended, stable operation of highly efficient biofilters with high toluene loadings. Environ. Sci. Technol., 30, 1744-1751.
Spain, J. C. and van Veld, P. A. (1983), Adaptation of natural microbial communities to degradation of xenobiotic compounds: effects of concentration, exposure, time, inoculum, and chemical structure. Appl. Environ. Microbiol., 45, 428-435.

U.S. EPA. (Environmental Protection Agency). Toxicological review of toluene in support of summary information on the Integrated Risk Information System (IRIS). U.S. Environmental Protection Agency, Washington, DC, EPA/635/R05/004, 2005.

Weber, F. and Hartmans S. (1996), Prevention of clogging in a biological trickle-bed reactor removing toluene from contaminated air. Biotechnol. Bioeng., 50, 91-97.

WHO. Air Quality Guidelines for Europe - Second Edition. Copenhagen, WHO Regional Office for Europe, 2000 (WHO Regional Publications, European Series, No. 91).

Zilli, M.; Palazzi, E.; Sene, L.; Converti, A. and Del Borghi, M. (2001), Toluene and styrene removal from air in biofilters. Process Biochem., 37, 423-9. 